\title{
Dever profissional entre pesquisadores de engenharias e áreas tecnológicas no Brasil e na Finlândia
}

\author{
Technological and engineering researcher's \\ professional duty in Brazil and Finland
}

\author{
Daniel Guerrini ${ }^{1}$ \\ ${ }^{1}$ Universidade Tecnológica Federal do Paraná | Departamento Acadêmico de Ciências Sociais \\ e Humanas \\ Londrina | PR | Brasil. Contato: danielguerrini@utfpr.edu.br \\ http://orcid.org/0000-0002-9125-2638
}

\author{
Renato de Oliveira ${ }^{2}$ \\ ${ }^{2}$ Centro Universitário Univates | Programa de Pós-Graduação em Ambiente e \\ Desenvolvimento \\ Lajeado | RS | Brasil. Contato: oliveira.remar@gmail.com \\ http://orcid.org/0000-0003-3096-2457
}
Resumo: Este artigo é resultado de uma pesquisa comparada entre pesquisadores de engenharias e áreas tecnológicas do Brasil e da Finlândia. O objetivo foi identificar as diferenças que cada grupo formulava a respeito de seu papel como pesquisadores em suas respectivas sociedades, conectando isso à sua percepção acerca do reconhecimento social de sua atividade. Foram entrevistados onze pesquisadores brasileiros e doze finlandeses. O questionário, de perguntas objetivas e abertas, se baseou em duas categorias: o reconhecimento social da atividade científica e a importância por eles atribuída a esta atividade. A partir da conexão entre essas duas categorias nas falas dos entrevistados, trabalhou-se com a noção de dever de cada grupo de pesquisadores, identificando como mobilizavam uma ideia de seu papel na sociedade. Conclui-se que, diante da falta de reconhecimento de suas atividades no Brasil, os entrevistados se veem na posição de desenvolver a sociedade. Diante do reconhecimento no caso finlandês, os entrevistados aprofundam a importância do caráter estritamente científico de sua atividade profissional.

Palavras-chave: Dever profissional. Sociologia da ciência. Sociologia do ensino superior.

Abstract: This article is the result of a compared investigation between engineering and technological researchers in Brazil and Finland. The aim was to identify the differences that each group formulated in respect of their role as researchers in their respective societies, connecting that to their perception about social recognition of their activity. We interviewed eleven and twelve researchers in Brazil and Finland respectively. The questionnaire, with objective and open questions, was based mainly in two categories: social recognition of scientific activities and the social importance by them attributed to it. From the connections between the to categories in the interviewee's answers, we worked with the notion of professional duty, identifying how both groups exposed an idea of their role in society. The work concludes that, faced with the lack of recognition of research activities in Brazil, the interviewees see themselves as promoters of social development. Faced with recognition of their activity, in Finland interviewees deepen the importance of the strictly scientific character of their professional activity.

Key words: Professional duty. Sociology of science. Sociology of higher education.

DOI: $10.1590 /$ S1414-40772019000100009

Este é um artigo publicado em acesso aberto (Open Access) sob a licença Creative Commons Attribution Non-Commercial, que permite uso, distribuição e reprodução em qualquer meio, sem restrições desde que sem fins comerciais e que o trabalho original seja corretamente citado. https://creativecommons.org/licenses/by-nc/4.0/ 


\section{Introdução}

Visões de mundo, teorias, ideologias, justificativas, conjuntos simbólicos em geral, mantêm relação com as posições sociais ocupadas pelos agentes que as exprimem. A partir dessa premissa básica é que este artigo analisa a perspectiva profissional de pesquisadores de engenharias e áreas tecnológicas situados em instituições de ensino superior (IES) no Brasil e na Finlândia. Perspectiva profissional é aqui entendida como as atribuições que os próprios agentes entendem ser parte de sua atividade de pesquisa, foco desta análise. É também nesse sentido que se fala em noção de dever profissional, uma noção elaborada pelos agentes acerca de sua atividade de pesquisa, compreendendo suas motivações e a importância que a ela atribuem na sociedade.

Esses agentes foram entrevistados com base em uma perspectiva qualitativa. As questões, parte objetivas e parte abertas, se basearam fundamentalmente em duas categorias: o reconhecimento social da atividade científica e a importância por eles atribuída a essa atividade. A questão do reconhecimento social permitiu observar como os pesquisadores liam a sociedade e suas expectativas em relação à academia. Por isso, essa categoria deu indícios do ambiente social vivido pelos pesquisadores e como nele se posicionam. A segunda categoria, a da importância social, explicita esse posicionamento, delineando o papel que se atribuíam e à atividade científica na sociedade.

Foi então possível elaborar uma terceira categoria, esta efetivamente analítica: a noção de dever dos pesquisadores. Dependendo como percebiam o reconhecimento social de suas atividades e, a partir disso, a importância que atribuíam à pesquisa na sociedade, os agentes mobilizavam uma noção de dever como pesquisadores. A atividade de pesquisa, nesse sentido, tinha um papel a cumprir em suas falas. Sua noção de dever profissional, a depender de suas condições de atuação, se remetia ora às regras internas da atividade e seu papel especializado na vida social, ora à necessidade de desenvolver a sociedade, sendo estas as diferenças de perspectiva entre pesquisadores finlandeses e brasileiros respectivamente.

Como argumentam Seale e Silverman (1997), buscou-se não apenas a autenticidade do material coletado, mas também sua confiabilidade, analisando como os agentes mobilizam a noção de dever profissional em seu discurso e como enquadram o papel da ciência no ambiente social do qual fazem parte. Para esse propósito foram enumeradas as ocorrências de categorias sendo investigadas em cada grupo nacional, analisando transversalmente as entrevistas com base nessas categorias (COMBESSIE, 2004). 
Fez-se uso do RQDA, um pacote de análise qualitativa de dados do programa R, software open source de análise de dados. Isto deu suporte às generalizações teóricas desta pesquisa. Foram realizadas, ao todo, vinte e três entrevistas, onze no Brasil e doze na Finlândia. A maior parte delas foi realizada e gravada por Skype, software VoIP (voice over internet protocol), com exceção daquelas realizadas na Universidade Tecnológica de Tampere, Finlândia, realizadas pessoalmente, como parte de uma pesquisa financiada pela CAPES - Coordenação de Aperfeiçoamento de Pessoal de Nível Superior.

Para as entrevistas, foram selecionados agentes ligados à pesquisa tecnológica e de engenharias. Escolheram-se essas áreas de pesquisa para analisar profissionais em contato direto com setores da sociedade externos à academia. Isto deu um sentido específico às questões sobre o reconhecimento social de suas atividades e a importância que atribuíam a estas. A partir disso, brasileiros e finlandeses formulavam uma noção de dever profissional, elaborando seu papel na sociedade com base na percepção que tinham dela. Pode-se, assim, estabelecer diferenças de perspectiva profissional nos dois ambientes selecionados.

Para comparar países tão distintos entre si, requer-se algum grau de similaridade entre fenômenos analisados para que a operação não se revele mera justaposição de diferenças. Afinal, por que comparar Brasil e Finlândia?

O ponto inicial é o caráter sub-industrializado das sociedades brasileira e finlandesa durante o século XX. Até meados da década de 1980, a Finlândia apresentava um quadro de industrialização muito aquém do padrão dos países europeus desenvolvidos e de baixa densidade tecnológica. As exportações realizadas majoritariamente para a União Soviética eram de commodities ou de produtos de baixo valor agregado. Com a crise da União Soviética, grande importadora de produtos finlandeses, a Finlândia passou por um período de recessão econômica que foi superada a partir da década de 1990 com a articulação de uma política de inovação que fez interagir indústrias e universidades, através da qual o país alterou profundamente o cenário de sua base industrial-tecnológica (HÄMÄLÄINEN, 2004; NIEMINEN; KAUKONEN, 2004).

O Brasil, por sua vez, manteve suas dificuldades em estabelecer interações entre universidades e o setor produtivo século XXI a dentro, mesmo estas sendo o objetivo de muitas iniciativas políticas e discursos oficiais dos gestores e instituições responsáveis pela pesquisa no país. A própria Lei da Inovação no Brasil, de 2004 (n. 10.973), explicita, já em seu artigo $1^{\circ}$, o objetivo de alcançar o desenvolvimento e a autonomia tecnológica através da pesquisa. Mas, Marco Antônio Raupp (2010), então presidente da SBPC, afirmava na abertura da $62^{\mathrm{a}}$ Reunião Anual desta entidade que transformar conhecimento em riqueza para o país 
era um objetivo ainda a ser alcançado pelos cientistas nacionais. Em 2016, na 68 Reunião da mesma entidade, os especialistas Edson Hirokazu Watanabe, então diretor da Coppe e professor de programa de engenharia elétrica da Universidade Federal do Rio de Janeiro (UFRJ), e Leandro Tessler, professor associado do Instituto de Física Gleb Wataghin da Unicamp, disseram que a inovação ainda precisava sair do papel no Brasil, e que em relação a isso "[a]lguma coisa não está funcionando direito [...] É preciso transformar conhecimento em inovação" (MONTEIRO, 2016).

Nesse sentido, observa-se, entre os dois países, um ponto de partida em comum - a sub-industrialização, uma base produtiva de pouco valor agregado e de baixa densidade tecnológica -, o estabelecimento de parâmetros similares para a sua superação - fortalecer e estreitar as relações entre pesquisa científica e desenvolvimento econômico -, e resultados dissonantes - a Finlândia concretiza aquilo com o que o Brasil ainda se debate.

O intuito, para deixar claro, não é explicar essa diferença de percursos históricos das duas sociedades, mas observar como diferentes ambientes sociais, que tiveram um ponto de partida semelhante em um passado recente, se refletem em diferentes perspectivas profissionais entre pesquisadores acadêmicos. São profissionais diretamente envolvidos com o objetivo das políticas mencionadas, que é o de ser partícipe no processo de inovações tecnológicas orientadas ao desenvolvimento econômico.

No caso finlandês, o país conta com catorze universidades, sendo que todas desenvolvem pesquisa, duas delas dando mais ênfase à pesquisa tecnológica e em engenharias. São elas a Universidade Tecnológica de Tampere (TUT, na sigla em inglês) e a Aalto University, uma universidade recém-criada, que reuniu algumas instituições preexistentes na cidade de Helsinque, capital do país. Foram então entrevistados pesquisadores de ambas as instituições, com ênfase à TUT, pois se trata de uma universidade com mais tradição na pesquisa tecnológica (foram, ao todo, oito entrevistas na TUT e quatro na Aalto University).

No caso brasileiro, tem-se um sistema de ensino superior (SES) extenso e diverso. Selecionaram-se instituições que Balbachevsky e Holzhacker (2005) denominaram acadêmicas tradicionais, apresentando mais de $60 \%$ de professores doutores e $75 \%$ de professores em regime de tempo integral. Segundo as autoras, esses cortes representam instituições com forte orientação e investimentos em pesquisa, além de concentração de programas de doutorado. Entre elas, buscaram-se instituições com programas de pesquisa nas áreas tecnológicas e de engenharias considerados de excelência, baseado nas notas a eles atribuídas pela CAPES. Foram entrevistados seis pesquisadores da Universidade Federal do 
Rio de Janeiro, especificamente do Instituto Alberto Luiz Coimbra de Pós-Graduação e Pesquisa de Engenharia, a COPPE-UFRJ; e cinco pesquisadores da Universidade de São Paulo, especificamente da Escola Politécnica da USP, a Poli-USP.

Com a comparação, como assegura Morlino (1994), alcançaram-se resultados de maior relevância e um maior controle dos argumentos explicativos para os fenômenos investigados. Dado o limite de casos sendo comparados, optou-se por trabalhar os conceitos em intensão e não em extensão. Na lógica dos estudos comparados, intensão diz respeito às qualidades ou propriedades que constituem o conceito, enquanto extensão consiste dos elementos (exemplos) que constituem o conceito (MORLINO, 1994). Com o recorte aqui realizado, contrastam-se os dois casos com base em conceitos analíticos, tentando captar relações e características constitutivas da realidade investigada.

As conexões estabelecidas no momento da interpretação dos dados das entrevistas respeitam a divisão entre cultura, sociedade e personalidade. A primeira trata dos conjuntos simbólicos, dos sentidos compartilhados da realidade. A segunda trata das relações institucionalizadas, são as condições de existência, as regras, os impedimentos e incentivos dentro dos quais ocorrem a ação. Essas regras são, ainda que não imediatamente, materialização dos princípios e normas culturais. A terceira é a esfera de mediação entre as duas anteriores, em que se internaliza a cultura, dando sentido às ações, que ocorrem em meio a relações institucionalizadas (WEBER, 1991; HABERMAS, 1989; LADRIÈRE, 2001).

Ao realizar entrevistas, trava-se contato direto com as representações interiorizadas pelos agentes e que estes mobilizam para dar sentido às suas atividades. Essas atividades se efetivam em instituições específicas, que, por sua vez, estão enquadradas em um contexto cultural mais amplo. Essa relação entre instituições específicas (de ensino superior e pesquisa científica) e contexto cultural é observada apenas na maneira como os agentes entrevistados a percebem. Mas, estando sua percepção conectada à sua posição social, a partir das entrevistas é possível tirar conclusões sobre ela. As atitudes específicas e as concepções próprias acerca de sua atividade profissional expõem características institucionais que a abriga e os valores culturais que lhes dá sentido.

Nas falas, percebe-se claramente quando os agentes veem suas atividades confrontadas com as regras e exigências das instituições acadêmicas ou com os valores e demandas culturais externos à academia. Observa-se, também, nas falas dos entrevistados, quando seu ambiente social comporta, ou não, instituições que garantem a comunicação entre o mundo acadêmico e os mundos sociais não-acadêmicos. A maneira como os agentes interpretavam a relação entre suas atividades e o contexto cultural se dava na questão do reconhecimento 
social. Ao expressarem suas opiniões acerca do reconhecimento social da atividade de pesquisa em seus respectivos países, os entrevistados apresentavam a maneira como liam a sociedade e, consequentemente, como nela se posicionavam. Esse posicionamento era explicitamente captado na questão relativa à importância que eles atribuíam à atividade de pesquisa, justificando seu papel na sociedade.

Mesmo as perguntas objetivas, eram complementadas para que o entrevistado expusesse suas visões e justificasse suas respostas. Também em razão disso, às vezes as temáticas (a relação entre sociedade, empresários e/ou governos) se cruzavam em relação às perguntas previstas, conforme se poderá observar adiante nas análises do material. O roteiro da entrevista pode ser conferido como anexo deste artigo.

A seguir faz-se uma breve apresentação da articulação conceitual que confere inteligibilidade à realidade investigada.

\section{A noção de dever e a inteligibilidade da atividade de pesquisa em diferentes mundos sociais}

Acima, expôs-se algumas das categorias usadas na coleta e análise dos dados desta pesquisa. A noção de dever está no centro da sistematização teórica que fundamenta este artigo. Trata-se de uma categoria da filosofia da ética que foi, em mais de um momento na história, apropriada pela reflexão sociológica. Segue-se aqui a discussão proposta por Ladrière (2001), que refaz um percurso desde a discussão kantiana sobre a moral, sua apropriação pela sociologia weberiana e seu desembocar na teoria da ação comunicativa habermasiana.

O primeiro aspecto dessa discussão é epistemológico. Desde a discussão kantiana sabe-se que, como o ser humano não se autoproduz, é-lhe impossível conhecer-se como coisa em si, mas somente como fenômeno que acontece no mundo. A consequência metodológica é que só é possível observar o curso de uma ação no mundo e inferir, a partir dessa observação, quais foram as possíveis motivações que conduziram à sua execução. Essa é também a posição da sociologia weberiana. Reconhecendo esses limites à cognição da realidade social, as ciências sociais tornam-se rigorosamente empíricas quando abdicam da tentativa de conhecê-la em si. Estuda-se então a ação social como fenômeno, ou seja, tal como esta aparece no mundo. Do curso que esta ação assume é possível ao investigador conjecturar acerca do sentido da ação e, portanto, daquilo que a move (WEBER, 1991; HABERMAS, 1989; LADRIÈRE, 2001). 
Dessa fundamentação epistemológica e metodológica chega-se à compreensão teórica da sociologia da ética. Conjecturar, a partir da observação empírica, acerca do motivo de uma ação evidencia ao investigador os princípios aos quais este agente em observação se alinha e aos quais ele adere. Compreende-se seus compromissos valorativos e as consequências que isso tem para o curso efetivo de sua ação no mundo. Trata-se, nas ciências empíricas, de conjecturas e não certezas, pois é sempre possível que seja outro o motivo que move a ação que não aquele identificado pelo observador. Um bom exercício é imaginar qual seria o curso assumido pela ação se todos seus motivos fossem racionalmente determinados com relação a fins. De todo modo, este é sempre um recurso heurístico que aproxima a interpretação da realidade (WEBER, 1991).

Eis aí o núcleo da noção de dever, uma categoria com a qual o investigador identifica os compromissos valorativos que guiam a ação de um agente social. Entretanto, a sociologia se interessa não apenas pelos princípios que norteiam a ação, mas também pelo processo com que estes se formam. Segundo Ladrière (2001), a sociologia da ética examina as instâncias da vida social às quais se ligam os valores que fundam a vontade dos agentes. A formação dos valores com os quais se compromete durante o curso da ação é resultado da avaliação que esses agentes fazem do mundo, como o percebem, julgam, classificam e ordenam. Por isso, a conjectura acerca dos princípios que guiam uma ação é tão importante quanto o exame das instâncias sociais que os sustentam. A noção de dever expressa essa inserção de um agente no mundo segundo seus compromissos valorativos.

Se os valores estão ligados às instâncias sociais nas quais vive determinado agente; e se esses valores orientam o curso da sua ação, que a tornam um fenômeno observável e interpretável pela sociedade; logo, uma ação tem sempre em perspectiva a maneira pela qual ela aparecerá no mundo. Para isso, se mobiliza uma visão acerca deste mundo. Os agentes, nesse sentido, leem, avaliam, julgam, classificam e ordenam a sociedade à sua volta e agem de acordo com essa leitura, pois buscam o reconhecimento de sua ação.

Essa busca por reconhecimento está ligada às pretensões de validade que implicam toda ação social (nesse sentido, ações comunicativas). Nas sociedades modernas há uma tendência para que essas pretensões de validade sejam suscetíveis à crítica. Seu reconhecimento se faz, portanto, com base em parâmetros transparentes e acessíveis ao debate e não segundo critérios herdados e autoevidentes. Focando a questão da ciência, que interessa a este artigo, as pretensões de validade dizem respeito à veracidade das alegações. Um pesquisador e/ou cientista busca ser reconhecido pela veracidade daquilo que afirma sobre o mundo objetivo. Suas alegações sobre os fatos que pesquisa devem ser verificáveis. Há, 
portanto, busca por reconhecimento na verificabilidade das alegações (o que se pode observar no interior do grupo de pesquisadores) e na própria pretensão de que suas alegações são verificáveis (o que se pode observar na relação desta esfera de ação com aquelas externas a ela, estando cada qual articulada por suas instituições). O grupo em questão busca reconhecimento nesses dois polos de sua atividade e, consequentemente, legitimação na sociedade na qual se insere (HABERMAS, 1989).

Embora na reflexão weberiana original tinha-se a impressão de que o espaço social dos valores substantivos na sociedade moderna racionalizada fosse marginal e cada vez menor, Ladrière (2001) e Habermas (1989) concordam e atentam para a esfera profissional como uma guarida destes. No exercício profissional há preservação e elaboração de valores substantivos, mesmo com toda investida da racionalidade instrumental, o formalismo das regras e o predomínio das ações econômica e administrativa no mundo moderno. Dentro desses grupos, e aí se incluem os da ciência, há preservação de elementos qualitativos orientando a ação de seus membros em contraposição à prevalência de uma calculista razão instrumental. Cria-se, nesse sentido, uma noção de dever profissional. Essa diz respeito aos objetivos que este grupo persegue, seus valores e ideais, levando-se em consideração o mundo no qual se inserem (LADRIÈRE, 2001; HABERMAS, 1989).

A seguir, com a análise do material empírico se observará como as instâncias da vida social de cada país fundamentam compromissos valorativos distintos entre os grupos entrevistados. Cada grupo elabora uma noção de dever profissional, se inserindo distintamente no mundo.

\section{A institucionalização da atividade de pesquisa pressupõe seu reconhecimento?}

Uma das primeiras constatações na análise das entrevistas dos pesquisadores brasileiros é a percepção generalizada sobre a falta de reconhecimento social da atividade científica no país.

\section{Quadro 1 - Percepção sobre o reconhecimento social da atividade científica no Brasil}

\begin{tabular}{|c|c|c|}
\hline \multirow{2}{*}{ Questão da entrevista: Na sua opinião, a atividade científica tem reconhecimento da sociedade? } \\
\hline \multirow{2}{*}{ Número de pesquisadores } & \multicolumn{2}{|c|}{ Respostas } \\
\cline { 2 - 3 } & Sim & Não \\
\cline { 2 - 3 } & 3 & 8 \\
\hline
\end{tabular}

Fonte: Elaboração própria; 
Dos onze entrevistados, oito foram categóricos em afirmar que esse reconhecimento não existe. Os três outros, apesar da resposta positiva, fizeram ressalvas. Para um deles, havia reconhecimento da mídia e dos pares, mas não do governo, que não paga bem os pesquisadores e criam leis como a Lei de Licitações n. 8.666 de 1993, denominada por ele como lei do controle - em sua opinião, o maior problema da ciência no Brasil. Outra pesquisadora, apesar de afirmar que havia sim reconhecimento, deixou claro que se tratava de um otimismo da sua parte. Segundo ela

A resposta da sociedade é lenta. A universidade olha os problemas de forma não-convencional. Quando a comunidade externa percebe a necessidade desse olhar, ela vem buscar o olhar novo da universidade para as coisas. Sou otimista (Pesquisadora em Engenharia Civil e Ambiental da PoliUSP).

O terceiro pesquisador que respondeu positivamente, refere-se à mídia que já o buscou para dar entrevistas, tratando-o com um respeito e cuidado, "até mais do que deveria". Entretanto, para ele não existem boas universidades em todas as regiões do país.

Em torno das boas cidades, regiões e estados existem. Até por que não é por acaso; porque você tem ali uma sociedade, um grupo mais bem preparado. Naquele entorno eu acho que há um reconhecimento sim (Pesquisador em Planejamento Energético da COPPE-UFRJ).

Na realidade, foi comum a percepção de que a questão do reconhecimento deveria ser fracionada. Seja sob o critério socioeconômico da população - em que as populações de baixa renda e menos instruídas, maioria da sociedade brasileira, não veem valor na atividade científica - seja sob o prisma de categorias profissionais - a mídia reconhece, mas os políticos não - seja sob o prisma do nível educacional e até mesmo sob a divisão entre comunidade interna e externa à própria universidade.

Alguns elementos das respostas sobre reconhecimento social chamam a atenção. Primeiro, a percepção comum a muitos entrevistados de que a população em geral olha para a academia com certo ar de admiração por algo desconhecido, indefinido, não entendendo para quê ela serve. Um dos pesquisadores fez a seguinte consideração,

Gosto de fazer o que eu faço. Gosto de pensar em problemas difíceis, procurar métodos de resolver esses problemas, trabalhar com os alunos para resolver esses problemas. Eu gostaria que isso tivesse uma relevância social. Que isso fosse valorizado institucionalmente - quer dizer institucionalmente é, por que você consegue publicar, etc. Mas fico chateado que o país em si não valoriza muito isso. A gente passa por uma categoria de pessoas que ficam em uma torre de marfim, que fazem coisas que não têm nenhuma utilidade prática, o que você não vê lá fora, onde as pessoas procuram a universidade para resolver seus problemas (Pesquisador em Engenharia Química da Poli-USP).

Outra pesquisadora diz ainda

Acho que a sociedade não demonstra esse reconhecimento, mas por desconhecer o que é feito. Mas acho que se as coisas fossem divulgadas, tivesse uma política... (Pesquisadora em Engenharia Química da Poli-USP). 
Fica claro que as pretensões de validade deste grupo profissional no Brasil não encontram reconhecimento, não podendo, portanto, serem legitimadas. Há, entre os próprios entrevistados, uma percepção de significativo distanciamento e alheamento da sociedade em geral em relação à produção científica. Na visão dos próprios pesquisadores, a sociedade não enxerga a universidade e a atividade científica como uma instituição e uma prática profissional enraizadas socialmente, mas como elementos cindidos das atividades 'normais' e 'úteis' da vida cotidiana. Essa é a percepção dos pesquisadores a respeito da sociedade, e o que servirá de parâmetro para o sentido que darão às suas atividades no interior de suas instituições. É importante reter aqui essa percepção de alheamento com relação à sociedade não-acadêmica.

Um pesquisador justifica esse alheamento dizendo que "A academia está sempre milhas à frente em campos relativamente novos" (Pesquisador em Planejamento Energético da COPPE-UFRJ). Desse ponto de vista, é irrealista esperar que o público em geral tome conhecimento do que é produzido em termos de conhecimento científico e a falta de reconhecimento torna-se naturalizada.

No mesmo sentido, outro pesquisador que não percebe reconhecimento da sociedade, diz que a sociedade "não entende para que serve a academia" e que

O reconhecimento não deve ser o grande norteador da carreira acadêmica. Vai ser uma consequência do trabalho bem feito. Não é isso que vai motivar a pesquisa. Trabalho que visa o reconhecimento é um trabalho que está sujeito à fraude (Pesquisador em Engenharia Biomédica da COPPE-UFRJ).

Observa-se, nessa fala, a interiorização do que Merton (2013) chamou de desinteresse do éthos científico. Segundo esse princípio normativo, nortear-se pelo reconhecimento seria elevar o interesse pessoal acima do interesse científico em si. Mas o que particulariza a resposta é o valor do desinteresse estar associado ao não reconhecimento social, ou seja, à certeza, por parte do entrevistado, de que a sociedade sequer "entende" a academia. Isso não desqualifica a interiorização de um valor próprio desse grupo profissional, mas o particulariza e serve, nesta análise, para compreender as diferenças de ambientes institucionais em que se enquadram pesquisadores brasileiros e finlandeses, que, como se verá, também objetivam o trabalho dentro das normas científicas, mas não percebem falta reconhecimento social.

É preciso enfatizar como essas respostas dão sentido às relações institucionalizadas em que se situam os pesquisadores no exercício de suas atividades. É lidando e refletindo sobre o reconhecimento social que os entrevistados percebem a sociedade e nela se posicionam. Mapeiam, descrevem, classificam, julgam, analisam e respondem ao que percebem. Adiante 
se observa outros detalhes acerca dessa percepção de como sociedade lida com a atividade científica.

Os pesquisadores observam que empresários e a indústria de modo geral não valorizam a atividade científica. A maioria disse trabalhar ou já ter trabalhado com organismos externos à academia, mas, dos onze entrevistados, nove consideravam fraco o reconhecimento dessa categoria. Um entrevistado disse que não podia reclamar, mas que se considerava um ponto fora da curva, pois fazendo pesquisa sobre a questão energética surgiam demandas, por exemplo, da Petrobras, que o permitiam escolher projetos com muita liberdade. Na realidade, a Petrobras aparece como a grande investidora em pesquisa tanto para pesquisadores da COPPE-UFRJ como da Poli-USP. Mas, excetuando essa empresa brasileira, a maioria das parcerias com agentes externos se dá ou com organismos internacionais (Banco Mundial e British Council) ou com setores da administração pública (Ministérios e um relato de trabalho realizado com a prefeitura de São Paulo).

\section{Quadro 2 - Percepção sobre a valorização do trabalho de pesquisa por empresários no Brasil}

\begin{tabular}{|c|c|c|}
\hline \multirow{2}{*}{ Questão da entrevista: Os empresários valorizam / reconhecem seu trabalho de pesquisa? } \\
\hline \multirow{2}{*}{ Número de pesquisadores } & \multicolumn{2}{|c|}{ Respostas } \\
\cline { 2 - 3 } & Positiva & Negativa \\
\cline { 2 - 3 } & 2 & 9 \\
\hline
\end{tabular}

Fonte: elaboração própria

Para uma das pesquisadoras (Engenharia civil e ambiental da Poli-USP), no Brasil as “empresas (são) pouco acostumadas a utilizar pesquisa". Três dentre os entrevistados relataram casos em que agentes da indústria mostraram interesse pelo seu trabalho científico, mas, quando deparados com os gastos e procedimentos necessários para estabelecer a parceria e/ou acordo, não deram mais respostas. O relato de uma das pesquisadoras segue assim,

Esse é o grande gargalo na relação universidade-empresa. A empresa quer muito produto de prateleira. Ele tem um problema e acha que a universidade já tem uma solução pronta. [...] $O$ empresário não quer saber se vai demorar seis meses pra investigar... Isso é uma coisa que assusta eles: o tempo que leva pra fazer esse trabalho, não é mágica (Pesquisadora em Engenharia Química da Poli-USP).

Dois outros pesquisadores criticaram as empresas brasileiras que lhes pareciam querer ser sustentadas pela universidade, ou por demandarem produtos prontos, de prateleira, ou por se aproveitarem de condições vantajosas, como mão de obra qualificada e barata (estudantes bolsistas) e laboratórios equipados prontos para serem utilizados. 
Para os pesquisadores, a relação com o Estado também não está livre de conflitos. Dos onze entrevistados, sete relataram problemas com a burocracia envolvida em seus trabalhos por conta de demandas que vem do Estado. Comum nessas falas foi a sensação de que políticos tratam aos pesquisadores como potenciais malfeitores, parecendo haver uma desconfiança institucionalizada. Nas palavras de um dos entrevistados,

São muito restritivas as regras pra gente [...] cada centavo tem de ser justificado, tribunal de contas, não sei o quê. Isso toma muito, muito, muito tempo. [...] A gente como pesquisadores, sendo bastante sincera, é como se a gente partisse do princípio que a gente não é honesto (Pesquisadora em Engenharia Química da Poli-USP).

A comparação com a política, esfera onde se veem muitos escândalos, casos de corrupção e lavagem de dinheiro, foi comum a outros entrevistados. Esse controle exercido pelo governo é visto como causa do desperdício de tempo e dinheiro a que são submetidos os pesquisadores no cotidiano de suas atividades. Três entre eles relataram que, nos últimos anos de suas vidas profissionais, estavam exercendo habilidades de gestores e administradores muito mais que de pesquisadores propriamente. Ao reclamarem dessa desconfiança institucionalizada, era comum a comparação com outros países (EUA e países europeus) em que os procedimentos para compra de equipamentos e manutenção de laboratórios são mais céleres e eficientes, dando-lhes enorme vantagem em relação à produção científica se pensada do ponto de vista da competitividade internacional.

O governo, na perspectiva dos entrevistados, submete a atividade científica a um controle que não é comum a todos os setores da sociedade e da administração pública. Fato é que as relações entre acadêmicos e empresários, governos e sociedade em geral passam todas por uma espécie rotura comunicativa. Elas estão baseadas em comportamentos estereotipados, ou seja, cada parte age com base em uma expectativa estereotipada do outro - e.g. acadêmicos malfeitores, sociedade atrasada, burocratas arbitrários, empresários imediatistas, etc. Ao negar que seu trabalho seja "mágica", a pesquisadora citada resiste exatamente a uma forma de estereotipação de seu trabalho.

As pretensões de validade aqui não se encontram suscetíveis à crítica e ao debate. Parece existir aí, como diz Habermas (1990; 2007), uma institucionalidade inacessível aos processos comunicativos. No caso das instituições que abrigam a pesquisa científica no Brasil, as relações mantidas por seus agentes com setores e grupos externos a elas têm dificuldade de ultrapassar o âmbito das expectativas já enraizadas e herdadas, ou seja, da estereotipação. Como parte da sua teoria da ação comunicativa, Habermas (1989; 1990; 2002) discute o quanto a institucionalidade das sociedades contemporâneas por vezes se fecha aos processos comunicativos da sociedade civil e de seus espaços públicos. Esse fechamento 
implica uma perda de legitimidade, na medida em que os agentes sociais não veem essas instituições como sendo responsivas às suas demandas, anseios e discussões. Nesse sentido pode-se explicar casos de roturas comunicativas em que haja pouca compreensão acerca de determinadas atividades sociais e profissionais.

A diferença em relação à teoria habermasiana é que ela discute sociedades cujas estruturas sociais foram amplamente racionalizadas, e este é o motivo de certas esferas de ação se tornarem inacessíveis aos processos comunicativos, obstando o debate público. Nelas, o debate é substituído por decisões técnicas, pretensamente neutras e, por isso, eficazes. Os grupos e setores da sociedade não influenciariam as decisões e os processos institucionais com seus interesses particulares para o benefício de relações sociais tornadas sistemas (em especial a economia e a administração pública), cientificamente fundadas e, por isso, supostamente válidas para todos (HABERMAS, 1989; 1990; 2002; 2007). Isso pressupõe uma sociedade em que o conhecimento técnico e científico está, ou foi, tão bem assentado e enraizado na sociedade que seus argumentos passam a substituir visões particulares que compõem a sociedade e o debate entre as mesmas.

Esse não é o caso brasileiro. Como já demonstrava em suas análises Oliveira (1985), a institucionalização da atividade científica e tecnológica no Brasil enfrentou muitas dificuldades, fundando um ambiente hostil e situações frágeis para seus agentes em termos de carreira e continuidade de suas atividades profissionais. Casos como aquele analisado por Faria (1997), em que um importante instituto de pesquisa científico é extinto em razão de mudanças ministeriais da vida política, já na década de 1960, explicitam exatamente essa fragilidade e o quão recente é a efetiva consolidação de instituições que abrigam a pesquisa científica no país. Na reforma do ensino superior de 1968, a formação pós-graduada do corpo docente ainda era um recurso escasso nas instituições de ensino superior brasileiras. No início do século XXI o título de doutorado havia se difundido, mas as instituições então passavam a enfrentar o problema de recompensar e avaliar a produtividade acadêmica stricto sensu (i.e. publicações) (BALBACHEVSKY, 2007).

Logo, ainda que o processo de rotura comunicativa seja semelhante àquele discutido por Habermas $(1990 ; 2002 ; 2007)$, eles têm causas distintas. No caso brasileiro, a própria institucionalidade assim se constitui, sobre processos comunicativos precários e cindidos, não sendo este o resultado da sobreposição e o predomínio da racionalidade instrumental na vida social, mas da permanência de visões herdadas e estereotipadas entre as diferentes esferas sociais. 
Weber (1982) faz uma discussão interessante para pensar a realidade brasileira. Tratase da ideia de grupos de status negativamente privilegiado. Tanto a falta de reconhecimento e alheamento da sociedade em geral como a desconfiança a que os pesquisadores se sentem submetidos pelo governo podem ser lidos através dela. Segundo Weber (1982), os grupos de status formam-se com base em uma expectativa positiva ou negativa da honraria, ou seja, de uma qualidade social partilhada pelos membros do grupo. A honra, portanto, está ligada a um estilo de vida reconhecido socialmente. A precipitação desse reconhecimento no grupo e em seus membros é o que Weber (1982) denomina dignidade dos grupos de status. Quando se tem um grupo socialmente aceito, não pelo reconhecimento de seu estilo de vida usurpado (monopolizado), mas por sua indispensabilidade econômica (no caso brasileiro, pensa-se na indispensabilidade da ciência e da tecnologia para as sociedades modernas), tem-se um estamento negativamente privilegiado. A questão é que as honrarias, nesse caso, não são reconhecidas socialmente. Isso não quer dizer um estado de animosidade entre grupo e sociedade em geral, mas apenas que possa existir aceitação e estabilização (no caso, até institucionalização) sem reconhecimento. Entretanto, diz Weber (1982), o grupo assim aceito, convicto da sua própria importância, projeta a sua dignidade no futuro, pois inexistente atualmente. Exatamente essa questão será colocada pelos entrevistados, conforme se observará.

Interessante é que, apesar do controle orçamentário e dos gastos de dinheiro público, muitos entrevistados relataram um alto grau de liberdade acadêmica. Apenas um dos pesquisadores relatou ter abandonado um trabalho para um ministério, pois durante o percurso percebeu que queriam forçar resultados específicos, e aquilo extrapolou seus limites. Mas conta como isso foi um episódio, e que, de modo geral, fruía de grande liberdade na escolha de seus temas e na condução de suas pesquisas. O controle aí observado é, nos termos de Clark (1983) e Berdahl (1990), mais burocrático que político, o que fica evidente nessas falas onde há críticas contundentes ao controle dos meios de se fazer pesquisa, e quase ausência de qualquer parâmetro sobre seus fins, como definição de temas interessantes política e socialmente.

Quadro 3 - Percepção sobre a interferência de governos na atividade de pesquisa

\begin{tabular}{|} 
Questão da entrevista: As avaliações dos governos e suas medidas de regulação do trabalho científico afetam de \\
alguma maneira suas atividades? \\
\hline \multirow{2}{*}{ Número de pesquisadores } & \multicolumn{2}{|c|}{ Respostas } \\
\cline { 2 - 3 } & Positiva & Negativa \\
\cline { 2 - 3 } & 0 & 11 \\
\hline
\end{tabular}


Fonte: Elaboração própria

Explanando a esse respeito, um dos pesquisadores diz,

Existe uma coisa boa da liberdade de pesquisa. Mas acho que a sociedade, através do governo, deveriam ser mais ativos em dirigir algumas linhas de pesquisa. Exceto em temas de editais e temas específicos, a gente não sente nenhuma motivação, por exemplo, dentro da universidade, para montar um grupo de pesquisa em torno de um tema (Pesquisador em Engenharia Metalúrgica da Poli-USP).

Outros pesquisadores também relatam essa ausência de qualquer interesse em definir temas de pesquisa com alguma relevância.

Nós temos de buscar lá fora conhecimento novo e tentar aplicar aqui. O governo não regulamenta isso não, a gente vai e faz (Pesquisadora em Engenharia Química da Poli-USP).

Para outro pesquisador (Planejamento estratégico da COPPE-UFRJ), não existe problema de interferência do governo nos trabalhos acadêmicos, mas uma desconsideração pelos relatórios e resultados produzidos pelas pesquisas realizadas em seu programa de pósgraduação.

Ao que tudo indica, pesquisadores brasileiros usufruem de um alto nível de autonomia. Mas o que caracteriza essa autonomia dificilmente foi discutido na literatura sobre ensino superior ou nos textos de sociologia da ciência. A autonomia que se vê nas falas dos pesquisadores tem um caráter negativo. Ela está ligada ao alheamento da atividade de pesquisa em relação à sociedade em geral e, além disso, a uma espécie de desinteresse dos governo em relação à mesma. Há nas falas coletadas uma percepção de que a sociedade em geral e os governos têm a pesquisa como uma atividade irrelevante. A liberdade observada não expressa uma relação de autonomia baseada no reconhecimento da atividade especializada, mas na indiferença dos governos e, portanto, na irrelevância atribuída a essa atividade por diversos setores da sociedade - tal como é percebido pelos próprios entrevistados. Como reflexo, os parâmetros buscados pelos pesquisadores às suas atividades é o 'conhecimento produzido lá fora'. Como dito anteriormente, são reflexos de uma institucionalização sem reconhecimento social. Em última instância, está-se falando de institucionalização sem processos de legitimação bem assentados.

Dois pesquisadores relataram o descompromisso do governo com relação à atividade científica sob outro prisma. Foram críticos dos 'modismos' dos editais e da ausência de uma política centrada e de longo prazo. Nas palavras de um deles,

O que se vê muito é uma atitude muito momentânea, inspirada por questões atuais, por exemplo aparece um programa que vai mandar quatro mil pessoas para o exterior. Não se vê uma estrutura para isso. Não se vê uma política centrada, de longo prazo. Entra governo, sai governo e as coisas mudam, as prioridades mudam. Por exemplo, houve a farra do biodiesel [...] As pesquisas todas eram muito repetidas, ninguém realmente inovava. De repente o governo jogou uma dinheirama nisso e de repente acabou. Descobriram o pré-sal e morreu (Pesquisador em Engenharia Química da Poli-USP). 
Dessa maneira, as políticas que definem alguma orientação e investimentos para a pesquisa científica têm pouco a ver com algum tipo de reconhecimento da academia e do potencial da atividade científica na estruturação dessas políticas. Estão, sim, ligadas a interesses circunstanciais da própria esfera política. Interesses esses que são instrumentalizados pelos pesquisadores, realizando pesquisas repetitivas e pouco inovadoras, já que recursos estão disponíveis para tanto. Outro exemplo de rotura comunicativa.

\section{Como, então, justificar a atividade de pesquisa no Brasil?}

Por fim, analisou-se o valor atribuído à atividade científica pelos entrevistados. Todos os entrevistados, sem exceção, veem a ciência como sendo importante para o desenvolvimento da sociedade brasileira. Oito dentre eles veem a atividade científica como a única saída para o desenvolvimento, relacionando-a principalmente à superação da dependência tecnológica através da geração de inovações na economia. Os outros três enquadraram a ciência como mais um dos elementos constituintes de uma realidade mais ampla, equivalente em importância aos outros elementos. Denominou-se essa diferença de atribuição de valor à ciência como absoluta e relativa.

\section{Quadro 4 - Atribuição de importância à atividade de pesquisa para a sociedade brasileira}

\begin{tabular}{|c|c|}
\hline \multicolumn{2}{|c|}{ Questão da entrevista: Você acha que atividades de pesquisa são importantes para seu país? Por quê? } \\
\hline \multicolumn{2}{|c|}{ Respostas } \\
\hline \multicolumn{2}{|c|}{ Sim } \\
\hline Atribuição de valor absoluto à pesquisa / ciência & Atribuição de valor relativo à pesquisa / ciência \\
\hline 8 & 3 \\
\hline
\end{tabular}

Fonte: Elaboração própria

Exemplificando, seguem expressões atribuindo valor relativo às atividades de pesquisa:

se a gente desenvolve tecnologia que otimiza processos, a gente está em última instância tornando toda a cadeia mais produtiva (Pesquisador em Engenharia Biomédica da COPPE-UFRJ).

Sim. Ela é importante de várias maneiras. Como uma produtora direta de conhecimentos de interesse tecnológico. Por outro lado a própria prática científica ajuda a criar um espírito crítico nas pessoas. Elas se tornam, elas passam a analisar as coisas de uma maneira mais racional, o que pode ser interessante. (Pesquisador em Engenharia Metalurgista da Poli-USP)

Acho que sim. Acho que há um crescente entendimento de que a universidade e a academia tem sim uma contribuição a fazer no Brasil no sentido de desenvolvimento de tecnologia e ferramentas que 
possam ajudar a destravar umas travas que o Brasil tem hoje (Pesquisador em Planejamento Energético da COPPE-UFRJ).

Essas três perspectivas não sobrepõem a ciência aos outros elementos da vida social com a qual ela se relaciona. No caso da fala sobre a cadeia produtiva de um determinado setor, a ciência é vista como otimizadora de processos, ou seja, ela se enquadra como um dos elos desta cadeia. A segunda fala apenas se remete a conhecimento de "interesse tecnológico", ou seja, cria-se um conhecimento que está disponível a potenciais interesses, que a incorporarão. Além disso, o segundo exemplo remete à formação da população, sendo possível que interiorizem uma visão racional sobre o mundo. Mas o pesquisador não vê isso como condição necessária para qualquer tipo de melhoria na vida dessas pessoas, apenas comenta, "o que pode ser interessante". Não há nisso nada de necessário, absoluto ou inevitável. Na terceira fala a perspectiva racionalizada está menos clara, mas o pesquisador enquadra a ciência como um dos elementos que contribui para "destravar" questões da sociedade. Como se pode perceber, a categoria de valor relativo, formulada para compreender as falas, diz respeito a uma noção de exercício especializado do trabalho profissional.

Abaixo, expressões em que a ciência aparece como um valor absoluto para a vida social,

então, o país como o Brasil, se ele não quer ser dependente da importação de tecnologia, [a ciência] é vital (Pesquisador em Planejamento Energético da COPPE-UFRJ).

Fundamental, como qualquer outro país do mundo. [...] Conhecimento científico está na ponta, na fronteira do conhecimento (Pesquisador em Planejamento Energético da COPPE-UFRJ).

É essencial! Veja o panorama das nações. Qual a única solução para um país sem recursos naturais? É o conhecimento. $O$ conhecimento é fundamental e é base do crescimento de todo capitalismo nanico, com população mínima, e sobrevive muito bem baseado exclusivamente em conhecimento (Pesquisador em Engenharia metalúrgica da COPPE-UFRJ).

É sem dúvida! Porque um povo ignorante não vai pra lugar nenhum (Pesquisadora em Engenharia química da Poli-USP).

Muito! Não há progresso e desenvolvimento sem atividade de pesquisa. Ela é a ponta de lança do desenvolvimento de longo prazo (Pesquisadora em Engenharia Civil e Ambiental da Poli-USP).

O contraste com as três falas anteriores é bastante evidente. Nas falas imediatamente supracitadas, a ciência aparece como a única saída que o país tem para se desenvolver, para progredir, para, enfim, ser capaz de "ir" a qualquer lugar. A ciência também aparece como a ponta de lança do desenvolvimento, à frente de qualquer outra atividade ou processo da vida social no seu conjunto. Aqui, a ciência certamente não é apenas mais um dos elementos constitutivos do desenvolvimento do país. 
Ressalva-se que a categorização de valor absoluto e relativo é uma operação analítica dos investigadores para compreender a realidade. Como procedimento, ela não tem o sentido de trazer à tona uma alegação sobre a verdade última do sentido das falas. Quer-se apenas ressaltar os elementos relevantes a essa investigação, para a qual as diferenças apontadas são suficientemente claras.

Aliada à forte percepção de descaso dos governos e distanciamento com relação à sociedade, essa atribuição de uma importância absoluta à atividade científica conecta-se com a discussão weberiana sobre o privilegiamento negativo de determinados grupos sociais. Há aí projeção de sua importância para o futuro, dado seu não reconhecimento atual. A ciência torna-se vital para o Brasil sair da condição de país dependente, de povo ignorante, para o país desenvolver-se no longo prazo, etc. É nesse sentido que se gesta uma noção de dever profissional entre esses entrevistados. Seu papel na sociedade está ligado ao desenvolvimento, ao fim da dependência tecnológica, à sustentabilidade econômica com base em produção de conhecimentos, à elevação dos níveis educacionais da população, quanto mais percebendo que o país, hoje, carece de todos esses elementos.

\section{A comparação: o que acontece quando há percepção de reconhecimento social da pesquisa?}

A fim de controlar a análise até agora esboçada, compara-se o caso finlandês a partir de uma questão sobre motivação profissional. Nas entrevistas, procurou-se saber o que motivava os pesquisadores em seu trabalho diário e as respostas foram enquadradas usando duas categorias, a da curiosidade fundamental e a da utilidade social. Ora os pesquisadores declaravam se mover por uma ideia de entender um fenômeno em si e explicá-lo cientificamente, ora por uma ideia de que o conhecimento que produziam seria útil à sociedade.

No Brasil, dos onze entrevistados, sete responderam que sua motivação para realizarem pesquisas estava ligada a uma curiosidade fundamental, ou ao desafio de produzir 'coisas novas'. Quatro dos entrevistados relataram ser a utilidade do conhecimento sua principal motivação. Logo, a maior parte dos entrevistados assumiu um compromisso com a atividade científica em si mesma.

Esse aspecto é mais forte na Finlândia. Dos doze entrevistados, onze relataram que suas motivações estão ligadas à atividade científica em si, à curiosidade e à descoberta de 'coisas novas'. 


\section{Quadro 5 - Motivações profissionais}

\begin{tabular}{|c|c|c|}
\hline \multicolumn{2}{|c|}{ Questão da entrevista: Quais suas motivações para buscar uma carreira como pesquisador? } \\
\hline \multicolumn{2}{|c|}{ Respostas } \\
\hline Curiosidade fundamental & Utilidade social \\
\hline \multicolumn{2}{|c|}{ Brasil } \\
\hline \\
\hline 11 & Finlândia & 4 \\
\hline
\end{tabular}

Fonte: Elaboração própria

Os finlandeses foram mais enfáticos quanto à importância dessa curiosidade fundamental que os brasileiros. Um deles, por exemplo, disse,

Essa é a parte mais criativa do trabalho, e geralmente é uma espécie de efeito eureka, em que você trabalha por vários dias, semanas sobre um problema até que você diz "essa deve ser a solução" e essa é a parte mais recompensadora do trabalho (Pesquisador em Engenharia e Ciência da Automação da Universidade Tecnológica de Tampere). ${ }^{1}$

Além disso, dois dos entrevistados finlandeses negaram que o interesse por ajudar a sociedade, a população em geral, tenha alguma influência decisiva no seu trabalho, enfatizando o quanto os aspectos técnicos e específicos à sua profissão são mais valorizados.

É claro, quero dizer, as pessoas tendem a pensar que existem impactos de longo prazo na indústria e no bem-estar da população finlandesa, no bem-estar do mundo e por aí vai, mas eu diria que a motivação principal é a curiosidade (Pesquisador em Engenharia e Ciência da Automação da Universidade Tecnológica de Tampere). ${ }^{2}$

A valorização da curiosidade científica pela maioria dos entrevistados evidencia um processo bem assentado de socialização nas instituições científicas nos dois ambientes nacionais. Mas, apesar da aparente semelhança, interessam aqui as diferenças.

Relembre-se o caso do pesquisador brasileiro que criticava a motivação por reconhecimento social na condução de pesquisas acadêmicas, formulando o que se enquadrou como o valor do desinteresse do ethos científico. Por sua vez, os finlandeses, ao demonstrarem adesão às normas da atividade científica, rejeitam mais enfaticamente a utilidade social como sua máxima. O contraste revela os ambientes em que se situam esses profissionais.

1 Tradução livre de: That is the most creative part of the work, and usually it is some sort of eureka effect, that you work several days, weeks around the problem until we say 'this must be the solution' and that is the most rewarding part of the work.

2 Tradução livre de: Of course I mean, one tends to think that it has some long term impacts on the industry and well being of finnish people, and well being of the world and so on, but I would say still that primary (motivation) it's the curiosity. 
A resposta do pesquisador brasileiro está contextualizada em um ambiente de ausência de reconhecimento social, o que é determinante para a sua fala. Perseguir tal reconhecimento significaria desviar do curso sugerido pelas normas científicas. Essa rotura entre acadêmicos e sociedade permite ao agente perseguir seus próprios valores sem obstáculos. Esse sentido negativo da liberdade acadêmica, aliás, também se evidenciou na relação de indiferença que pesquisadores brasileiros percebiam por parte dos governos, como observado anteriormente.

Na Finlândia, a crítica à busca por reconhecimento não faz sentido, uma vez que este se encontra bem assentado (ver quadro 6 adiante). Já a crítica à utilidade se contextualiza, como se pode ler na citação supracitada, em uma sociedade que nutre expectativas de geração de bem-estar e desenvolvimento econômico com relação à ciência. Atender a essas expectativas é que, neste caso, desviaria o agente das normas de seu mundo profissional.

Ao expor a sua relação com o empresariado, um pesquisador finlandês diz,

quando eles [empresários] introduzem um problema para nós, geralmente nós podemos ver o fenômeno que está por trás, fenômeno que você pode aplicar em diferentes sistemas e indústrias (Pesquisador em Ciência dos Materiais da UTT). ${ }^{3}$

Apesar de interesses diversos, não há aí conflito entre o ponto de vista científico e o empresarial. Cada qual valoriza e se interessa, nesse encontro, por aquilo que é próprio de sua atividade econômica e social. E essa comunicação é possível sem que os agentes finlandeses tenham de aderir, eles mesmos, à questão da utilidade do conhecimento. Habermas (2007), em 'Ciência e Técnica como Ideologia', aborda essa questão, dizendo que, desde Galileu, a ciência moderna desenvolveu uma predisposição técnica, de aplicabilidade dos seus conhecimentos, não do ponto de vista subjetivo (isto é, do ponto de vista dos valores dos cientistas), mas do ponto de vista da forma. Permite-se assim um engajamento racional (não particularista) dos pesquisadores no meio social em que vivem. Os pesquisadores não necessitam, portanto, ter eles próprios a motivação pela solução de problemas imediatos, pois a predisposição técnica foi incorporada como forma nas suas atividades e está contida no próprio marco metodológico das mesmas.

Esta pesquisa se ocupa em interpretar os dados que foram coletados, o que tornaria inócua qualquer tentativa de iniciar uma discussão epistemológica abstrata sobre diferentes formas de fazer ciência. Como se observa, especialmente no caso finlandês, mesmo que o conhecimento produzido seja utilizado por setores externos à academia, isso não implica um engajamento subjetivo por parte dos pesquisadores que, pelo contrário, movem-se, isto sim,

3 Tradução livre de: when they introduce that problem to us, very often we can see the phenomena behind, phenomena you can apply in different systems and industry. 
por uma curiosidade científica fundamental. Investigar questões fundamentais da ciência não conflita com a apropriação prática destes conhecimentos. Não há, portanto, necessidade de uma orientação adicional por parte dos pesquisadores além daquele que sua especialidade e competência científica requerem. Esse engajamento com o setor produtivo é, como dito acima, racional e não subjetivo.

Como já adiantado, a seguir se observa que na Finlândia nenhum pesquisador relatou falta de reconhecimento da atividade científica por parte de empresários, governo ou sociedade em geral.

Quadro 6 - Percepção sobre o reconhecimento social da atividade científica na Finlândia

\begin{tabular}{|c|c|}
\hline \multicolumn{2}{|c|}{ Questão da entrevista: Na sua opinião, a atividade científica tem reconhecimento da sociedade? } \\
\hline \multicolumn{2}{|c|}{ Respostas } \\
\hline Sim & Não \\
\hline 12 & 0 \\
\hline
\end{tabular}

Fonte: Elaboração própria

Alguns ressalvaram sobre a diferença entre o "tempo" da universidade e o "tempo" das empresas. Entretanto, essa crítica sempre se encontrou resolvida pela existência da Agência Finlandesa de Fomento à Inovação - TEKES - que financia pesquisas acadêmicas em colaboração com empresas (em que estas também aportam recursos para condução de pesquisas). Os projetos financiados por essa agência têm garantidos, segundo os entrevistados, o tempo tanto para chegar a soluções práticas, como para ir mais a fundo nos temas de seu interesse científico e tecnológico. Em outros casos, os pesquisadores se remeteram à Academy of Finland, outra agência de fomento, mas sem orientação para a inovação, que também financiava alguns projetos tanto da Universidade Tecnológica de Tampere como da Aalto University.

Todos os entrevistados finlandeses consideraram que o empresariado nacional reconhecia suas atividades. Cinco deles ainda enfatizaram uma boa relação com as empresas.

As indústrias finlandesas entendem que se querem desenvolver algo novo, e algo melhor do que seus competidores, você tem de entender o processo e o que está por trás, não apenas a técnica da tentativa e erro [sic]. Por exemplo, por que usar esse tipo de material? (Pesquisador em Ciência dos Materiais da UTT). ${ }^{4}$

4 Tradução livre de: Finnish industry understand that if they want to develop something new, and something better than their competitors you have to understand the process and what is behind. not just the trial and error technique. For example, why use this kind of material?. 
Até mesmo em relação ao "tempo" de cada setor, um pesquisador disse que algumas "empresas compreendiam essa diferença" (Pesquisador em Engenharia Química da Aalto University). Outro relatou também que

As empresas ficam surpreendidas que o problema possa ser resolvido dessa maneira (Pesquisador Ciência e Engenharia da Automação da UTT) ${ }^{5}$

No caso ele se refere ao conhecimento da dinâmica por trás do sistema (uma linha de produção, máquinas de automação, etc.) em questão.

Posta a percepção de reconhecimento social da atividade científica, vê-se como isso reflete na atribuição de importância social à pesquisa pelos entrevistados. A diferença é que, neste caso, as instituições específicas parecem canalizar de modo eficaz os processos comunicativos entre agentes internos e externos à academia. Nessas circunstâncias, nenhum pesquisador finlandês sobrepôs os interesses da atividade científica aos da sociedade em geral. Todas as respostas elaboraram em torno do papel especializado que desempenham na sociedade.

\section{Quadro 7 - Atribuição de importância à atividade de pesquisa para a sociedade finlandesa}

\begin{tabular}{|c|c|}
\hline \multicolumn{2}{|c|}{ Questão da entrevista: Você acha que atividades de pesquisa são importantes para seu país? Por quê? } \\
\hline \multicolumn{2}{|c|}{ Respostas } \\
\hline \multicolumn{2}{|c|}{ Sim } \\
\hline Atribuição de valor absoluto à pesquisa / ciência & \multicolumn{1}{c|}{ Atribuição de valor relativo à pesquisa / ciência } \\
\hline 0 & \\
\hline
\end{tabular}

Fonte: Elaboração própria

A seguir, algumas respostas.

Mas o que podemos fazer é bastante simples. [...] pessoas fazendo experimentos tanto em física como em química. Então quando você faz mensurações precisas, então a computação é bastante útil. (Pesquisador em Química e Física Computacional da Aalto University). ${ }^{6}$

Eu diria que não é tão fácil para os produtores aqui. Eles tem de ter um sobrevalor para seus produtos e o sobrevalor vem do trabalho de pesquisa (Pesquisador em Automação e Hidráulica Inteligente da $U T T)^{7}$

Nós precisamos ter alguma coisa a mais o que [sic] nós produzimos usando nossos cérebros, por que a força de trabalho aqui é relativamente cara. [...] A sociedade se beneficia mais que estou [sic] fazendo

5 Tradução livre de: Companies become surprised that the problem can be solved in that way.

6 Tradução livre de: But what we can do is quite simple. [...] people doing experiments, either physics or chemistry. So when you do precise measurements then the computation is very usefull

7 Tradução livre de: I would say that it is not so easy for the manufacturers here. They have to have some extravalue for their products. And the extra-value comes from the research work. 
esse tipo de trabalho do que se estou fazendo agricultura [sic] [risos] (Pesquisadora em Biomateriais da $U T T)^{8}$

Como no caso brasileiro, esse aspecto da fala dos entrevistados está ligado à percepção do reconhecimento social da atividade científica. Os pesquisadores finlandeses têm claro esse reconhecimento, logo, sua dignidade social não se projeta no futuro, mas se realiza, concreta e atualmente, no exercício especializado da sua profissão. Não existe tentativa de mostrar o potencial que a atividade dispõe, pois a sociedade já o reconhece e demanda.

A importância atribuída à atividade de pesquisa está ligada, no caso finlandês, à sua especialização. Os entrevistados não fazem de sua atividade fator imprescindível para o país e condição absoluta para que este chegue a um novo patamar econômico, social ou cultural. Os pesquisadores sentem-se parte da dinâmica social sem exibirem uma percepção de alheamento como no Brasil. O dever profissional, nesse caso, liga-se à especificidade de sua competência, do exercício atual de sua atividade, que assim contribui com a sociedade, aumentando a produtividade da indústria e gerando um sobrevalor para os produtos desta. O que confere sentido à sua atuação não é desenvolver a sociedade, ou retirá-la da condição de atraso e ignorância, mas ser um elo competente na cadeia de relações que constituem a vida social finlandesa.

Para a questão acerca da influência governamental sobre a atividade de pesquisa (número 5 do questionário), nenhum entrevistado da Finlândia explanou sobre essa temática, alguns se limitando a dizer que havia influência com programas de fomento e investimentos em áreas específicas que, por vezes, o governo de seu país executava. Apesar da brevidade das respostas, estas também contrastam com a dos pesquisadores brasileiros, que reclamavam sobre a falta de um direcionamento e até uma indiferença por parte dos governos com relação ao que produziam a partir de suas pesquisas.

\section{Conclusão}

A comparação da perspectiva profissional de pesquisadores no Brasil e na Finlândia mostrou-se bastante relevante para os objetivos desta pesquisa. Primeiramente, ela demonstra como questões que hoje parecem quase um consenso internacional acerca da atividade de pesquisa científica (i.e. sua utilidade e importância para o desenvolvimento econômico) guardam diferenças significativas em distintos ambientes sociais. Isso tanto no plano

8 Tradução livre de: we need to have something more what we produce using our brains, because workforce is relatively expensive here. [...] society bennefits more that I'm doing this kind of work than I'm doing agriculture (laugh). 
simbólico dos próprios pesquisadores como no plano prático, na efetividade dos acordos celebrados, ou não, entre pesquisadores e empresários de cada país. Como pano de fundo, isso reforça o argumento de estudiosos da sociologia da ciência de que determinadas generalizações sobre supostas "novas maneiras de se fazer ciência” são resultado de análises unilaterais (MARCOVICH; SHINN, 2012; FERREIRA, 2015), quando não de retórica política (MIETTINEN, 2002). A valorização da ciência por ela mesma existe, nos dias atuais, tanto quanto a valorização da ciência útil. Os casos analisados, inclusive, expõem a realidade de um país em que a intensa e frequente colaboração universidade-empresa não impede uma adesão clara dos pesquisadores a ideais puramente científicos.

Observaram-se diferenças também no plano da institucionalidade que abriga a atividade de pesquisa em um e outro país. Em um caso se observam processos comunicativos baseados na estereotipação dos agentes entre si, em outro, uma institucionalidade que canaliza e permite o encontro de visões e interesses, a princípio, divergentes. A incompatibilidade do 'tempo' da pesquisa com o 'tempo' da economia, assim como a divergência de interesses acerca da utilidade do conhecimento e da compreensão científica dos fenômenos, no caso finlandês, encontrava respaldo em agências de fomento, como a TEKES, que garantiam canais de comunicação entre mundos sociais distintos.

Os pesquisadores finlandeses, percebendo o reconhecimento da sociedade, elaboram um dever profissional que se encontra estreitamente vinculado à especialização de sua atividade. Seu papel, na sua própria concepção, é bastante circunscrito aos requisitos da atividade científica especializada e, nesse sentido, tampouco se engajam subjetivamente na produção de um conhecimento que será utilizado por agentes externos. Esse engajamento é, nas palavras de Habermas (2007), racional, pois presente na forma já de sua atividade profissional. Ficam, assim, resguardados seus interesses propriamente científicos, de compreensão e explicação da realidade e dos fenômenos. A sociedade finlandesa reconhece e se apropria desses conhecimentos, existindo, para isso, mecanismos institucionais efetivos.

No caso brasileiro, a percepção comum entre os pesquisadores foi a de falta de compreensão e de indiferença por agentes externos à academia. Não há alusão a mecanismos institucionais que solucionem ou amenizem esses choques de interesses e de compreensão. Pelo contrário, há sim alusão a mecanismos institucionais que reforçam essa rotura, como é o caso da Lei de Licitações, ou "do Controle", segundo a perspectiva nativa. Observa-se, portanto, uma rotura comunicativa entre mundo acadêmico e não-acadêmico, e a discussão weberiana sobre grupos negativamente privilegiados foi mobilizada para interpretar o fenômeno. Assim como argumentava Weber (1982), os pesquisadores brasileiros têm um 
espaço social próprio, mas não percebem o reconhecimento social. Esse descompasso faz com que sua dignidade social seja projetada no futuro, já que não se atualiza no presente. Assim se elabora o dever profissional desses pesquisadores, que se veem no papel de desenvolver a sociedade, de tirá-la da condição de dependência tecnológica e de esclarecer a população. Todos problemas que eles percebem claramente a partir de seu ponto de vista científico, mas cujas soluções enfrentam grandes dificuldades em se concretizar.

\section{Referências}

BALBACHEVSKY, Elisabeth; HOLZHACKER, Denilde O. A profissão acadêmica no Brasil: evolução nos últimos 10 anos. Documento de Trabalho do Núcleo de Pesquisas sobre Ensino Superior da Universidade de São Paulo, n. 2, 2005.

BALBACHEVSKY, Elisabeth. Carreira e contexto institucional no sistema de ensino superior brasileiro. Sociologias, Porto Alegre, v. 9, n. 17, jan./jun. 2007.

BERDAHL, Robert. Academic freedom, autonomy and accountability in British Universities. Studies in Higher Education, United Kingdom, v. 15, n. 2. 1990.

CLARK, Burton. The higher education system: Academic Organization in Cross-National Perspective. California: University of California Press, 1983.

COMBESSIE, Jean-Claude. O método em sociologia: o que é, como faz. São Paulo: Loyola, 2004.

FARIA, Lina Rodrigues de. Uma ilha de competência: a história do Instituto de Química Agrícola na memória de seus cientistas. História, Ciências e Saúde, Rio de Janeiro, v. 4, n. 1, mar./jun. 1997.

FERREIRA, Mariana Toledo. Trajetórias e divisão do trabalho no laboratório de genética humana. Scientiae Studia, São Paulo, v. 13, n. 4, 2015.

HABERMAS, Jürgen. The theory of communicative action. Boston: Beacon Press, 1989. v. 2.

HABERMAS, Jürgen. Soberania popular como procedimento: um conceito normativo de espaço público. Novos Estudos CEBRAP, São Paulo, n. 26, mar. 1990.

HABERMAS, Jürgen. A crise de legitimação no capitalismo tardio. Rio de Janeiro: Tempo Brasileiro, 2002.

HABERMAS, Jürgen. Ciencia y técnica como “ideologia”. 5. ed. Madrid: Tecnos, 2007. 
HÄMÄLÄINEN, Timo. Towards a theory of social innovation and structural change. In: SCHIENSTOCK, Gerd (ed.). Embracing the knowledge economy: the dynamic transformation of the Finnish Innovation System. UK: Edward Elgar Publishing, 2004.

LADRIÈRE, Paul. Pour une sociologie de l'éthique. Paris: PUF, 2001.

MARCOVICH, Anne; SHINN, Terry. Regimes of science production and diffusion: towards a transverse organization of knowledge. Scientiae Studia, São Paulo, v. 10, ed. esp., 2012.

MERTON, Robert King. Ciência e estrutura social democrática. In: MERTON, Robert King. Ensaios de Sociologia da Ciência. São Paulo: Associação Filosófica Scientiae Studia; Editora 34, 2013.

MIETTINEN, Reijo. National innovations systems: scientific concept or political rhetoric? Helsinki: University of Helsinki, 2002.

MONTEIRO, Viviane. Faltam engenheiros de PD\&I para tirar inovação do papel no Brasil. Jornal da Ciência, 12 de julho de 2016. Disponível em

$<$ http://www.jornaldaciencia.org.br/faltam-engenheiros-de-pdi-para-tirar-inovacao-do-papelno-brasil/>. Acesso em 27 de fevereiro de 2019.

MORLINO, Leonardo. Problemas y Opciones en la Comparación. In: SARTORI, G.;

MORLINO, L. La comparación en las ciencias sociales. Madrid: Alianza Editoria, 1994.

NIEMINEN, Mika; KAUKONEN, Erkki. Universities and science-industry relationships: making virtue out of necessity. In: SCHIENSTOCK, Gerd (ed.). Embracing the knowledge economy: the dynamic transformation of the Finnish Innovation System, UK: Edward Elgar Publishing, 2004.

OLIVEIRA, João Batista A. Ilhas de competência: carreiras científicas no Brasil. São Paulo: Brasiliense, 1985.

RAUPP, Marco Antônio. Discurso do Presidente da SBPC. Disponível em:

<http://www.sbpcnet.org.br/livro/62ra/presidente.htm>. Acesso em 27 de fevereiro de 2019.

SEALE, Clive; SILVERMAN, David. Ensuring rigour in qualitative research. The European Journal of Public Health, Holanda, v. 7, n. 4, p. 37-384, dez. 1997.

WEBER, Max. Economia e sociedade: fundamentos da sociologia compreensiva. Brasília: UnB, 1991. v. 1.

WEBER, Max. Ensaios de sociologia. Rio de Janeiro: Guanabara Koogan, 1982. 